\title{
Неупругое рассеяние горячих фотоэлектронов при выходе в вакуум из p-GaAs(Cs,O)
}

\author{
В.В. Бакин ${ }^{1}$, С.А. Рожков ${ }^{1,2}$, С.Н. Косолобов ${ }^{1}$, Г.Э. Шайблер ${ }^{1,2}$, А.С. Терехов ${ }^{1}$ \\ ${ }^{1}$ ИФП СО РАН, Новосибирск, 630090, пр. Ак. Лаврентьева, \\ ${ }^{2}$ Новосибирский государственный университет, Новосибирск, 630090, ул. Пирогова, 2 \\ тел:+7 (913) 789-0912, эл.nочma: bakin@ngs.ru
}

DOI 10.34077/RCSP2021-126

Полупрозрачные $\mathrm{p}$ - $\mathrm{GaAs}(\mathrm{Cs}, \mathrm{O})$-фотокатоды $\mathrm{c}$ эффективным отрицательным электронным сродством (ОЭС) применяются в настоящее время в электронно-оптических преобразователях, координатно-чувствительных детекторах, в источниках спин-поляризованных и монохроматических электронов. Каждая из областей практического применения требует оптимизации параметров р$\mathrm{GaAs}(\mathrm{Cs}, \mathrm{O})$-фотокатода. Научно-обоснованный подход к такой оптимизации предполагает, что хорошо известны: атомная структура ОЭС-интерфейса, его энергетическая диаграмма и процессы рассеяния, сопровождающие выход фотоэлектронов в вакуум. Наиболее информативный метод изучения энергетической диаграммы и процессов рассеяния основан на анализе энергетических и угловых распределений эмитированных в вакуум фотоэлектронов. С помощью данного метода, ранее, были проанализированы энергетические [1] и угловые [2] распределения термализованных фотоэлектронов. В результате, была предложена модель, в которой предполагалось, что выход в вакуум представляет собой “двухступенчатый процесс" и сопровождается “промежуточным захватом” фотоэлектронов в приповерхностные зоны размерного квантования.

В данной работе исследовалась фотоэмиссия горячих (нетермализованных) фотоэлектронов. Для экспериментов использовался $\mathrm{p}-\mathrm{GaAs}(\mathrm{Cs}, \mathrm{O})$-фотокатод с тонким активным слоем $\left(\mathrm{d}_{\mathrm{GaAs}} \sim 0.7\right.$ мкм $)$ в котором горячие фотоэлектроны составляли заметную часть от общего числа эмитированных в вакуум частиц. На рисунке сплошной линией показано распределение фотоэлектронов по продольной энергии $\left(\mathrm{n}_{\mathrm{e}}\left(\varepsilon_{\text {lon }}\right)\right)$. Точками показана производная $\left(\mathrm{n}_{\mathrm{e}}{ }_{\mathrm{e}}\left(\varepsilon_{\mathrm{lon}}\right)\right)$ от высокоэнергетической части распределения

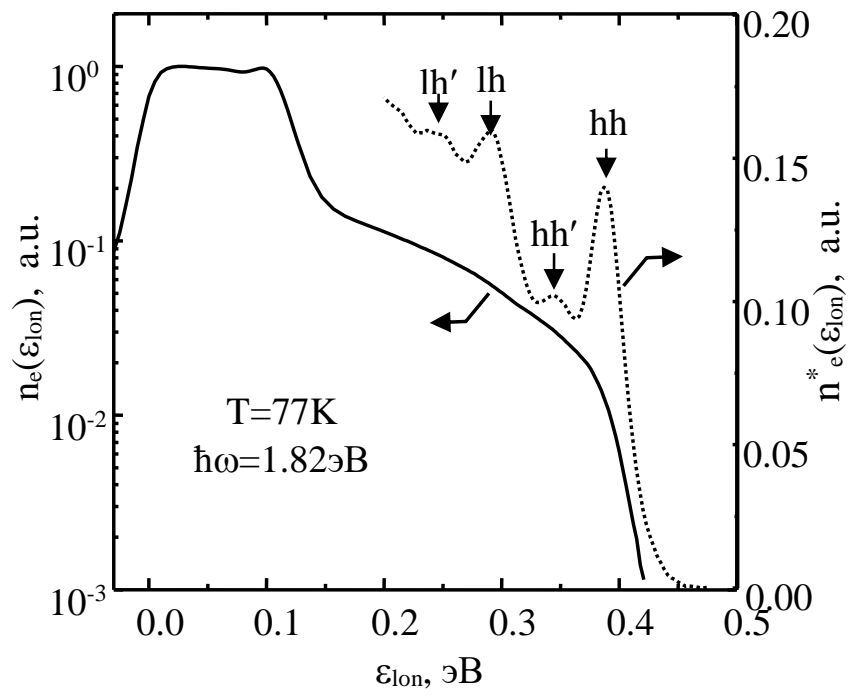
$\mathrm{n}_{\mathrm{e}}\left(\varepsilon_{\text {lon }}\right)$. В производной видны особенности hh и lh - соответствующие электронам, возбуждённым из зоны тяжёлых и лёгких дырок, а также фононные реплики этих особенностей $h^{\prime} h^{\prime}$ и $\mathrm{lh}^{\prime}$, смещенные относительно основных пиков на $\sim 40$ мэВ. Изменение $ћ \omega$ возбуждающего света приводило к смещению всех пиков по шкале энергий. При этом положения пиков $\mathrm{hh}$ и $\mathrm{lh}$ менялось в соответствии с зонной структурой GaAs. Из этого следует, что электроны, формирующие пики $\mathrm{hh}$ и $\mathrm{lh}$, сохраняют свою начальную энергию, которую они получили в момент фотовозбуждения, и выходят в вакуум в "баллистическом режиме" - без захвата в зону размерного квантования. Фононные реплики пиков hh и $\mathrm{lh}$ свидетельствуют о том,

что часть фотоэлектронов в процессе такого “одноступенчатого" выхода в вакуум испускают оптический фонон. Полученный результат ставит под сомнение модель “двухступенчатого” выхода с промежуточным захватом фотоэлектронов в приповерхностные зоны размерного квантования, так как появляются основания полагать, что и тонкая структура в энергетических распределениях $[1,2]$ сформирована фотоэлектронами, термализованными на дно зоны проводимости и вышедшими в вакуум в “одноступенчатом режиме”. Работа выполнена при поддержке РФФИ (проект 19-02-00517).

\section{Лuтература}

[1] Д.А. Орлов и др. // Письма в ЖЭТФ. 2000. Т.71, вып.4. С.220-224 .

[2] В.В. Бакин и др. // Письма в ЖЭТФ. 2003. Т.77, вып.4. С.197-201. 